\title{
Studying composite demand using scanner data: the case of ground beef in the US
}

\author{
Lee L. Schulz ${ }^{\mathrm{a}, *}$, Ted C. Schroeder ${ }^{\mathrm{b}}$, Tian $\mathrm{Xia}^{\mathrm{c}}$ \\ a Department of Economics, Iowa State University, 478D Heady Hall, Ames, IA 50011, USA \\ ${ }^{\mathrm{b}}$ Department of Agricultural Economics, Kansas State University, 219 Waters Hall, Manhattan, KS 66506, USA \\ ${ }^{\mathrm{c}}$ Department of Agricultural Economics, Kansas State University, $331 B$ Waters Hall, Manhattan, KS 66506, USA
}

Received 14 June 2011; received in revised form 24 April 2012; accepted 13 June 2012

\begin{abstract}
This article reports tests of aggregation over elementary ground beef products and estimates composite demand elasticities. Results suggest that we obtain reliable information on consumers' actual ground beef purchases by grouping data according to either lean percentage or brand type. The results also suggest that we obtain reliable information by using the data to form a single ground beef composite. By testing for valid aggregates and providing estimates of composite demand elasticities the analysis provides economists and policymakers with information regarding the effects of food and agricultural policies on consumers and producers that buy and produce ground beef.
\end{abstract}

JEL classifications: Q13, Q18, R32

Keywords: Aggregation; beef demand; Generalized Composite Commodity Theorem; ground beef

\section{Introduction}

Beef demand has fallen in recent years (Tonsor, 2012), motivating the beef industry to find ways to reverse this trend. At retail, consumers have increased their share of ground beef purchases. Scanner data representing ground beef purchases in U.S. retail outlets indicate that the quantity of ground beef relative to fresh beef purchased rose from $44 \%$ in 2004 to $48 \%$ in 2008. Furthermore, ground beef sales revenue expressed as a fraction of all fresh beef sales revenue increased from $33 \%$ in 2004 to $37 \%$ in $2008 .{ }^{1}$ To improve our understanding of this growing market, detailed quantitative analysis of ground beef demand is needed.

Ground beef is differentiated by brand and lean percentage. Store branding of ground beef increased from 7\% in 2004 to 37\% in 2010 (National Meat Case, 2010). Increased consumer preferences for low-fat ground beef (Brester et al., 1993; Lusk and Parker, 2009) has led to differentiation of ground beef by its lean percentage which varies from $70 \%$ to $100 \%$ lean. While ground beef is more differentiated than ever, there are

\footnotetext{
*Corresponding author: Tel: (515) 294-3356; fax: (515) 294-3838. E-mail address: 1schulz@iastate.edu (L. L. Schulz).

${ }^{1}$ Quantity (pounds) and revenue (dollars) of ground beef purchases were calculated from Freshlook Marketing Group data used in this analysis.
}

no published estimates of consumer demand elasticities for differentiated ground beef and no tests of how to aggregate ground beef.

Scanner data provide accurate volume-weighted pricing data revealing what consumers are purchasing and how much they are spending on products. However, using scanner data directly to estimate demand responses for ground beef may not be feasible as it would involve estimating large demand systems which might be associated with multicollinearity and computational difficulties. It would be necessary to aggregate over the vast number of products. Valid commodity aggregation could reveal the way in which consumers prefer to allocate expenditures over different groups of ground beef products or the information in ground beef prices might justify the formation of a single ground beef composite. Conversely, incorrect aggregation can result in large errors in elasticity and welfare estimates.

\section{Demand and aggregation}

The theory of commodity aggregation provides the conditions under which consumer demand for a vast number of elementary goods is accurately described by consumers whom act as if they are optimizing over a considerably smaller number of aggregate goods. In their survey of agricultural economics 
literature, Shumway and Davis (2001) identified 22 empirical studies that tested for consistent aggregation of food and/or agricultural commodities.

Until recently there have been two ways to justify commodity aggregation. First, separability (most often homothetic separability) is sufficient for commodity-wise aggregation (Deaton and Muellbauer, 1980). Separable preferences reveal the way in which consumers prefer to aggregate because their aggregation scheme is embedded in the structure of their utility functions. Thus, tests of aggregation based on separability are tests of the different ways consumers allocate their expenditures over groups of products. The problem is that because separable utility restricts the degree of substitution across goods, aggregation schemes based on separability are often rejected empirically (Eales and Unnevehr, 1988; Nayga and Capps, 1994; Diewart and Wales, 1995).

The second way researchers have justified commodity aggregation has been to appeal to the Composite Commodity Theorem (CCT; Hicks, 1939; Leontief, 1936). Instead of restricting utility functions and patterns of group expenditures, the CCT restricts movements in consumer prices. The problem is that the CCT requires the relative prices of the goods in any valid composite to be absolutely constant over time so that tests of commodity aggregation based on the CCT must always be rejected empirically.

More recently Lewbel (1996) developed the Generalized Composite Commodity Theorem (GCCT) which demonstrated that commodity aggregation can be justified by relaxing the stringent conditions of the CCT. Instead of requiring relative prices to be constant, the GCCT requires only that relative prices be statistically independent of group prices. This restriction generally concurs with the widely observed multicollinearity of prices over time, and more specifically requires that changes in relative prices of goods within a group be unrelated to the general rate of inflation of the group (Lewbel, 1996).

Numerous studies have used the GCCT to address how different elementary consumer goods (Asche et al., 1999; Asche et al., 2001; Capps and Love, 2002; Davis, 1998; Eales et al., 1998; Karagiannis and Mergos, 2002; Lewbel, 1996; Reed et al., 2003; Reed et al., 2005) or different agricultural supplies (Davis et al., 2000; Williams and Shumway, 2000) can be aggregated. This study applies the GCCT to (primary) scanner data to test for valid consumer demand composites and then provides econometric estimates of demand responses.

\section{Generalized composite commodity theorem}

This study applies the GCCT to scanner data of ground beef purchases because this theorem relaxes the restrictive requirements for aggregation implied by separable preferences and constant relative prices. This section briefly reviews the GCCT and restrictions required for commodity aggregation. The reader is referred to Lewbel (1996) for further details.

The GCCT maintains that $n$ elementary share equations are functions of logged elementary prices, $\mathbf{r}$, and logged income, $z$. Following Lewbel (1996), let $w_{i}(i=1, \ldots, n)$ denote the $i$ th elementary budget share and let $E$ denote the mathematical expectations operator. Then an elementary good's budget share $w_{i}(i=1, \ldots, n)$ is defined to be composed of a systematic Marshallian demand function $g_{i}(\mathbf{r}, z)$ plus an error term $e_{i}$ with a conditional mean zero such that,

$w_{i}=g_{i}(\mathbf{r}, z)+e_{i}$

where $E\left(e_{i} \mid \mathbf{r}, z\right)=0$ and $g_{i}(\mathbf{r}, z)=E\left(w_{i} \mid \mathbf{r}, z\right)$. Because the $g_{i}$ form a valid elementary demand system, they satisfy addingup $\left(\sum_{i=1} g_{i}(\mathbf{r}, z)=1\right)$, homogeneity $\left(g_{i}(\mathbf{r}-k, z-k)=g_{i}(\mathbf{r}\right.$, $z)$ for all $i)$, and Slutsky symmetry $\left(\left(\partial g_{k} / \partial r_{j}\right)+\left(\partial g_{k} / \partial z\right) g_{j}=\right.$ $\left.\left(\partial g_{j} / \partial r_{k}\right)+\left(\partial g_{j} / \partial z\right) g_{k}\right)$. The compensated demands satisfy negative semi-definiteness.

The theory also maintains the existence of a system of aggregate, or composite, share equations. The $N(<n)$ composite shares $W_{I}=\sum_{i \epsilon I} w_{i}(I=1, \ldots, N)$ are functions of logged composite prices, $\mathbf{R}$, and logged income, $z$. Specifically,

$\mathrm{W}_{I}=\mathrm{G}_{I}(\mathbf{R}, z)+\varepsilon_{I}$,

where $E\left(\varepsilon_{I} \mid \mathbf{R}, z\right)=0$ and $G_{I}(\mathbf{R}, z)=E\left(W_{I} \mid \mathbf{R}, z\right)$. Following Lewbel (1996), let $G_{I}{ }^{*}(\mathbf{r}, z)$ denote the sum of the conditional means of the elementary demands for group $I$, such that $G_{I}{ }^{*}(\mathbf{r}$, $z)=\sum_{i \in I} g_{i}(\mathbf{r}, z)$. Also define $\rho_{i}=r_{i}-R_{I}$ as the $i$ th relative price so the vector of all relative prices is $\boldsymbol{\rho}=\mathbf{r}-\mathbf{R}^{*}$ where $\mathbf{R}^{*}$ denotes the $n$-vector of group prices with $R_{I}$ in row $i$ and in every row $i \epsilon I$.

Lewbel (1996) demonstrates that valid aggregation is obtained when the vector of all relative prices, $\boldsymbol{\rho}$, is statistically independent of composite prices, $\mathbf{R}$, and income, $z$. This implies,

$$
\begin{aligned}
\int \mathrm{G}_{I}^{*}\left(\mathbf{R}^{*}+\boldsymbol{\rho}, z\right) d F(\boldsymbol{\rho}) & =E\left[G_{I}^{*}\left(\mathbf{R}^{*}+\boldsymbol{\rho}, z\right) \mid \mathbf{R}, z\right] \\
& =G_{I}(\mathbf{R}, z),
\end{aligned}
$$

which states that the composite budget share equation written in terms of the group price indices, $G_{I}(\mathbf{R}, z)$, is equal to the conditional expected value of the sum over the elementary budget share equations, $G_{I}{ }^{*}(\mathbf{r}, z)$, when the elementary prices are written as deviations from the group price indices, $\mathbf{R}^{*}+\boldsymbol{\rho}=\mathbf{r}$.

Lewbel (1996) uses (3) to obtain results that relate directly to demand system estimation. First, $G_{I}(\mathbf{R}, z)(I=1, \ldots, N)$ is a valid system of composite demand equations because this system inherits the adding-up, homogeneity, and nearly (or in some cases exactly) inherits Slutsky symmetry from the elementary demands. ${ }^{2}$ Second, the demand elasticities of $G_{I}(\mathbf{R}, z)$ are best, unbiased estimates of within-group sums of elementary demand elasticities.

\footnotetext{
${ }^{2}$ Composite demand equations satisfy the Slutsky symmetry condition, and so are integrable, if and only if the conditional covariance matrix is symmetric. However, even if the conditional covariance matrix is nonsymmetric it is likely to be small so that departures from Slutsky symmetry are likely to be small (Lewbel 1996, p. 527).
} 


\section{Empirical strategy}

The empirical section proceeds as follows. First, elementary ground beef data is tested for valid demand composites based on the GCCT. Second, if valid aggregation is found, composite demands are estimated with a Rotterdam model.

\subsection{Testing overview}

As stated earlier, empirical testing requires determining whether relative elementary prices $\left(\rho_{i}\right)$ are statistically independent of an aggregate price index for that group $\left(R_{I}\right)$. First, an aggregate group price index must be computed for each group $I$. Second, the relative prices are defined as: $\rho_{i}=r_{i}-R_{I}$, where $r_{i}=\ln p_{i}$ and $R_{I}=\ln P_{I}$.

Following Lewbel (1996), tests depend on time series properties of the data. Unit root tests are used to determine the stationarity of $\rho_{i}$ and $R_{I}$. Specifically, (1) if $\rho_{i}$ and $R_{I}$ are both stationary then a test for independence such as a correlation test is done, (2) if $\rho_{i}$ and $R_{I}$ are both nonstationary then a test for independence such as a cointegration test is done, (3) if $\rho_{i}$ is stationary and $R_{I}$ is nonstationary then aggregation is valid, and (4) if $\rho_{i}$ is nonstationary and $R_{I}$ is stationary then aggregation is valid. A result of no correlation or cointegration suggests the series are independent and can be aggregated. In cases (3) and (4), where one series is stationary (either $\rho_{i}$ or $R_{I}$ ) and the other is nonstationary, no test for independence is required because two series cannot be cointegrated if one is stationary and the other is nonstationary (Granger and Hallman, 1988).

\subsection{Rotterdam model}

The absolute price version of the Rotterdam model is used to estimate composite demand systems implied by the GCCT tests. See Theil (1980) for a detailed development of the Rotterdam model. This specification is chosen because it allows imposition of restrictions derived from consumer demand theory (symmetry and homogeneity) and is sufficiently flexible to capture variations in consumer behavior, especially demand elasticities (Brester and Wohlgenant, 1991; Capps and Love, 2002). Although the Rotterdam model is not derived from an underlying utility or expenditure function, it satisfies the integrability conditions when homogeneity and symmetry are imposed (Deaton and MuellBauer, 1980). The Rotterdam model handles nonstationary data easily as price and quantity variables are expressed in natural logarithmic differences, which is an advantage over other demand systems such as the Almost Ideal Demand System (Capps and Love, 2002; Capps et al., 2003). Rotterdam model use is common in demand system estimation using scanner data (Capps et al., 1997; Capps and Love, 2002; Nayga and Capps, 1994; Seo and Capps, 1997).
The $i$ th equation of the estimated model is given by:

$w_{i} \Delta \ln \left(q_{i}\right)=\theta_{i} \Delta \ln (Q)+\sum_{j=1} \pi_{i j} \Delta \ln \left(p_{j}\right)+v_{i}$,

where $w_{i}$ is the budget share of the $i$ th product (time subscripts $[t]$ on each variable are omitted for convenience); $\Delta$ is the standard first-difference operator [e.g., $\Delta \ln Y_{t}=\ln \left(Y_{t}\right)-\ln \left(Y_{t-1}\right)$ ]; $q_{i}$ is consumption of the $i$ th product; $p_{j}$ is the price of the $j$ th product; $\Delta \ln (Q)$ is the Divisia volume index [ $\sum_{i=1} w_{i} \Delta \ln \left(q_{i}\right)$ ]; $v_{i}$ is a random error term; and $\theta_{i}$ and $\pi_{i j}$ are parameters to be estimated.

Adding-up, homogeneity, and symmetry restrictions are imposed as maintained assumptions to ensure the demand model is consistent with theory. The adding-up restrictions are $\sum_{i=1} \theta_{i}=1$ and $\sum_{i=1} \pi_{i j}=0$. The homogeneity and symmetry restrictions are imposed, respectively, by $\sum_{j=1} \pi_{i j}=0$ and $\pi_{i j}=\pi_{j i}{ }^{3}$ If $\pi_{i j}>0$, then products $i$ and $j$ are substitutes; if $\pi_{i j}<0$, the respective products are complements, and if $\pi_{i j}=0$, the products are independent. The own- and crossprice compensated demand elasticities are $\varepsilon_{i j}=\pi_{i j} / w_{i}$. The expenditure elasticity is $\eta_{i}=\theta_{i} / w_{i}{ }^{4}$

\section{Data}

Scanner data allow significant advances in understanding food product marketing because they enable estimation of firm-, brand-, and commodity-level demand models (Cotterill, 1994; Capps and Love, 2002). Lensing and Purcell (2006) find that the prices collected by the Bureau of Labor Statistics (BLS) have been higher than the prices that consumers use to make their buying decisions. Volume weighted prices, provided by scanner data, more accurately reflect what consumers actually pay for fresh meat in contrast to BLS summaries of posted prices (Lensing and Purcell, 2006). Furthermore, use of simple average monthly prices biases own-price elasticities upward compared to weekly and volume-weighted price estimations because price change measures in BLS data are smaller for simple average monthly prices than for weekly prices or for volume-weighted prices (Lensing and Purcell, 2006).

Scanner data representing ground beef purchases in U.S. retail outlets from January 1, 2004, through March 31, 2009, were

\footnotetext{
${ }^{3}$ Models were estimated using the PROC MODEL procedure in SAS 9.2. Each system was estimated using iterated seemingly unrelated regression, with an allowance for common serial correlation across all equations. Starting values of 0.0001 were used.

${ }^{4}$ The variance of each elasticity estimate was obtained by the delta method. The delta method estimates the variance of a nonlinear function of two or more random variables by taking a first-order Taylor series expansion around the mean value of the variable and calculating the variance on that newly created random variable (Greene 2003). The delta estimates of the variances of the compensated price and expenditure elasticities are $\operatorname{var}\left(\varepsilon_{i j}\right)=\left(1 / \bar{w}_{i}^{2}\right) \times$ $\operatorname{var}\left(\hat{\pi}_{i j}\right)$ and $\operatorname{var}\left(\eta_{i}\right)=\left(1 / \bar{w}_{i}^{2}\right) \times \operatorname{var}\left(\hat{\theta}_{i j}\right)$, respectively. Using the variance of the elasticity estimates, $t$-values were computed and used to test for statistical significance for each estimate.
} 
Table 1

Percentage share of packages, revenue, and quantity of elementary ground beef products, January 1, 2004, through March 31, 2009

\begin{tabular}{|c|c|c|c|c|c|}
\hline Number & Brand type & Lean percentage & Packages (\%) & Revenue (\%) & Quantity (\%) \\
\hline 1 & Local/Regional & $70-77 \%$ & 4.39 & 0.45 & 0.52 \\
\hline 2 & National & $70-77 \%$ & 6.86 & 0.28 & 0.27 \\
\hline 3 & Store & $70-77 \%$ & 7.39 & 0.60 & 0.64 \\
\hline 4 & Unbranded & $70-77 \%$ & 5.64 & 38.40 & 46.17 \\
\hline 5 & Local/Regional & $78-84 \%$ & 1.61 & 0.13 & 0.11 \\
\hline 6 & National & $78-84 \%$ & 6.01 & 0.38 & 0.36 \\
\hline 7 & Store & $78-84 \%$ & 6.52 & 0.41 & 0.36 \\
\hline 8 & Unbranded & $78-84 \%$ & 2.35 & 20.68 & 21.23 \\
\hline 9 & Local/Regional & $85-89 \%$ & 2.79 & 0.04 & 0.02 \\
\hline 10 & National & $85-89 \%$ & 7.54 & 0.59 & 0.41 \\
\hline 11 & Store & $85-89 \%$ & 11.87 & 1.29 & 1.05 \\
\hline 12 & Unbranded & $85-89 \%$ & 3.52 & 11.32 & 10.27 \\
\hline 13 & Local/Regional & $90-95 \%$ & 3.19 & 0.06 & 0.04 \\
\hline 14 & National & $90-95 \%$ & 7.84 & 1.25 & 0.80 \\
\hline 15 & Store & $90-95 \%$ & 10.83 & 0.95 & 0.59 \\
\hline 16 & Unbranded & $90-95 \%$ & 3.28 & 20.36 & 15.48 \\
\hline 17 & Local/Regional & $96-100 \%$ & 1.84 & 0.16 & 0.11 \\
\hline 18 & National & $96-100 \%$ & 4.12 & 0.88 & 0.48 \\
\hline 19 & Unbranded & $96-100 \%$ & 2.39 & 1.78 & 1.09 \\
\hline
\end{tabular}

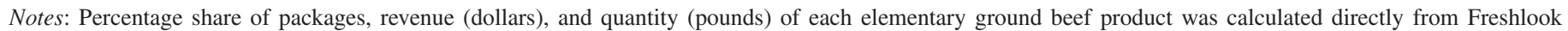
Marketing Group data.

obtained from Freshlook Marketing Group, which collects infoscan data on meat department random-weight sales from retail food stores nationwide. Data recorded for each sale included: revenue (dollars), quantity (pounds), price (dollars per pound), brand name, and lean percentage.

The data consisted of 64 different ground beef brands that were classified into the following categories: (1) local/regional-distributed within a local or regional geographic area and is owned and controlled by a private company, (2) national-distributed to retail locations nationwide and controlled by the company or the supplier(s) who owns the brand, (3) store-specific to a certain retail store or chain of stores and owned and controlled by the retail grocery store or chain of stores, or (4) unbranded-a product without a brand name on the label.

Ground beef is grouped by Freshlook Marketing Group into five lean percentage categories: (1) 70-77\%, (2) 78-84\%, (3) $85-89 \%$, (4) $90-95 \%$, or (5) 96-100\% lean. Data on store brands of $96-100 \%$ lean was not available. This is because within the ground beef market there are few transactions of this lean category. Table 1 provides the percentage share of packages, revenue, and quantity of each elementary ground beef product.

There are 19 ground beef products ( 4 brand types $\times 5$ lean percentages less the store brand $96-100 \%$ lean). The GCCT tests conducted involved three possible subsets of these products. Table 2 identifies the three groupings of products we tested for consistency with the GCCT. Common letters in each column indicate which products were hypothesized to be valid aggregates in a particular group. Groups A-E (Aggregation Scheme 1) consists of five ground beef composites that are differentiated based on lean percentage, groups F-I (Aggregation Scheme 2) consists of four ground beef composites differentiated by brand type, and group J (Aggregation Scheme 3) consists of a single ground beef composite.

Table 2

Generalized composite commodity theorem test groups

\begin{tabular}{|c|c|c|c|c|c|}
\hline \multirow[t]{2}{*}{ Number } & \multicolumn{2}{|l|}{ Commodity } & \multicolumn{3}{|c|}{$\begin{array}{l}\text { Aggregation } \\
\text { schemes }^{\mathrm{a}}\end{array}$} \\
\hline & Brand type & Lean percentage & 1 & 2 & 3 \\
\hline 1 & Local/Regional & $70-77 \%$ & A & $\mathrm{F}$ & $\mathrm{J}$ \\
\hline 2 & National & $70-77 \%$ & A & G & $\mathrm{J}$ \\
\hline 3 & Store & $70-77 \%$ & A & $\mathrm{H}$ & $\mathrm{J}$ \\
\hline 4 & Unbranded & $70-77 \%$ & A & I & $\mathrm{J}$ \\
\hline 5 & Local/Regional & $78-84 \%$ & B & $\mathrm{F}$ & $\mathrm{J}$ \\
\hline 6 & National & $78-84 \%$ & B & G & $\mathrm{J}$ \\
\hline 7 & Store & $78-84 \%$ & B & $\mathrm{H}$ & $\mathrm{J}$ \\
\hline 8 & Unbranded & $78-84 \%$ & B & I & $\mathrm{J}$ \\
\hline 9 & Local/Regional & $85-89 \%$ & $\mathrm{C}$ & $\mathrm{F}$ & $\mathrm{J}$ \\
\hline 10 & National & $85-89 \%$ & $\mathrm{C}$ & G & $\mathrm{J}$ \\
\hline 11 & Store & $85-89 \%$ & $\mathrm{C}$ & $\mathrm{H}$ & $\mathrm{J}$ \\
\hline 12 & Unbranded & $85-89 \%$ & $\mathrm{C}$ & I & $\mathrm{J}$ \\
\hline 13 & Local/Regional & $90-95 \%$ & $\mathrm{D}$ & $\mathrm{F}$ & $\mathrm{J}$ \\
\hline 14 & National & $90-95 \%$ & $\mathrm{D}$ & G & $\mathrm{J}$ \\
\hline 15 & Store & $90-95 \%$ & $\mathrm{D}$ & $\mathrm{H}$ & $\mathrm{J}$ \\
\hline 16 & Unbranded & $90-95 \%$ & $\mathrm{D}$ & I & $\mathrm{J}$ \\
\hline 17 & Local/Regional & $96-100 \%$ & $\mathrm{E}$ & $\mathrm{F}$ & $\mathrm{J}$ \\
\hline 18 & National & $96-100 \%$ & E & G & $\mathrm{J}$ \\
\hline 19 & Unbranded & $96-100 \%$ & $\mathrm{E}$ & I & $\mathrm{J}$ \\
\hline
\end{tabular}

${ }^{\mathrm{a} B r a n d}$ type and lean percentage rows sharing the same letter in each aggregation test group column are hypothesized to be in the valid aggregates in a particular product grouping. Groups A-E (Aggregation Scheme 1) consists of five ground beef composites that are differentiated based on lean percentage, groups F-I (Aggregation Scheme 2) consists of four ground beef composites differentiated by brand type, and group J (Aggregation Scheme 3) consists of a single ground beef composite. 
Table 3

Generalized composite commodity theorem test results for aggregation scheme 1 (Lean Percentage Composites)

\begin{tabular}{|c|c|c|c|c|c|}
\hline Group and relative prices & Aggregate share (\%) & ADF Test $\mathrm{H}_{0}: I(1)^{\mathrm{a}}$ & KPSS Test $\mathrm{H}_{0}: I(0)^{\mathrm{b}}$ & $I(0)$ or $I(1) ?^{c}$ & $\begin{array}{l}\text { Engle-Granger Test } \mathrm{H}_{0} \text { : } \\
\text { Not Cointegrated }(N C)^{\mathrm{d}}\end{array}$ \\
\hline & & $\tau_{t}$ & $\eta_{t}$ & & $T_{k}$ \\
\hline$R(70-77 \%)$ & & $-2.306(7)$ & $0.326(5)^{*}$ & $I(1)$ & \\
\hline$\rho($ Local/Regional $)$ & 1.22 & $-2.491(8)$ & $0.570(5)^{*}$ & $I(1)$ & $-2.982(4)$ \\
\hline$\rho$ (National) & 0.72 & $-3.411(9)^{*}$ & $0.254(5)^{*}$ & $I(0)(\mathrm{JCH})$ & $N C$ \\
\hline$\rho$ (Store) & 1.78 & $-3.420(6)^{*}$ & $0.252(5)^{*}$ & $I(0)(\mathrm{JCH})$ & $N C$ \\
\hline$\rho$ (Unbranded) & 96.28 & $-2.826(4)$ & $0.331(5)^{*}$ & $I(1)$ & $-2.809(4)$ \\
\hline$R(78-84 \%)$ & & $-2.945(5)$ & $0.191(5)^{*}$ & $I(1)$ & \\
\hline$\rho($ Local/Regional $)$ & 0.65 & $-2.570(6)$ & $0.281(5)^{*}$ & $I(1)$ & $-2.153(6)$ \\
\hline$\rho$ (National) & 1.80 & $-1.683(6)$ & $0.708(5)^{*}$ & $I(1)$ & $-1.734(6)$ \\
\hline$\rho$ (Store) & 1.98 & $-2.965(11)$ & $0.582(5)^{*}$ & $I(1)$ & $-3.265(10)$ \\
\hline$\rho$ (Unbranded $)$ & 95.56 & $-0.718(6)$ & $0.831(5)^{*}$ & $I(1)$ & $-0.437(6)$ \\
\hline$R(85-89 \%)$ & & $-2.759(6)$ & $0.277(5)^{*}$ & $I(1)$ & \\
\hline$\rho($ Local/Regional $)$ & 0.32 & $-4.634(3)^{*}$ & $0.399(5)^{*}$ & $I(0)(\mathrm{JCH})$ & $N C$ \\
\hline$\rho$ (National) & 4.44 & $-3.320(10)^{*}$ & $0.134(5)^{*}$ & $I(1)(\mathrm{JCH})$ & $-2.686(10)$ \\
\hline$\rho$ (Store) & 9.81 & $-1.519(7)$ & $0.557(5)^{*}$ & $I(1)$ & $-1.975(7)$ \\
\hline$\rho$ (Unbranded) & 85.44 & $-1.702(7)$ & $0.505(5)^{*}$ & $I(1)$ & $-1.934(7)$ \\
\hline$R(90-95 \%)$ & & $-2.618(11)$ & $0.433(5)^{*}$ & $I(1)$ & \\
\hline$\rho($ Local/Regional $)$ & 0.29 & $-1.370(4)$ & $0.441(5)^{*}$ & $I(1)$ & $-1.422(4)$ \\
\hline$\rho$ (National) & 5.53 & $-2.650(11)$ & $0.469(5)^{*}$ & $I(1)$ & $-2.263(11)$ \\
\hline$\rho$ (Store) & 4.23 & $-3.128(4)$ & $0.360(5)^{*}$ & $I(1)$ & $-2.933(8)$ \\
\hline$\rho$ (Unbranded) & 89.96 & $-2.698(10)$ & $0.604(5)^{*}$ & $I(1)$ & $-2.427(9)$ \\
\hline$R(96-100 \%)$ & & $-2.558(10)$ & $0.663(5)^{*}$ & $I(1)$ & \\
\hline$\rho($ Local/Regional $)$ & 6.49 & $-10.898(1)^{*}$ & $0.122(5)^{*}$ & $I(0)(\mathrm{JCH})$ & $N C$ \\
\hline$\rho$ (National) & 31.25 & $-3.750(8)^{*}$ & $0.087(5)^{*}$ & $I(0)$ & $N C$ \\
\hline$\rho$ (Unbranded) & 62.26 & $-2.974(9)$ & $0.185(5)^{*}$ & $I(1)$ & $-3.235(7)$ \\
\hline $10 \%$ critical values & & -3.130 & 0.119 & $(-3.391,0.114)$ & -5.727 \\
\hline
\end{tabular}

Asterisk $(*)$ denotes rejection of the null at the 0.10 significance level.

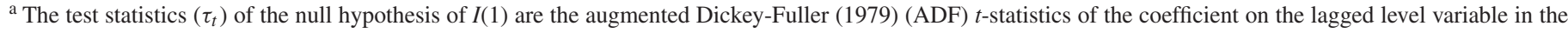

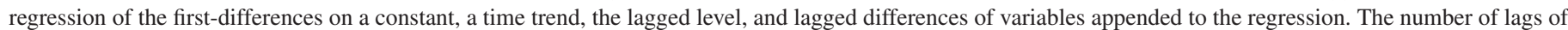
first differences is reported in parentheses and determined by 2.10 .1 .

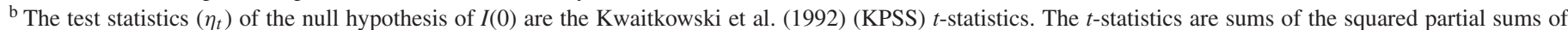

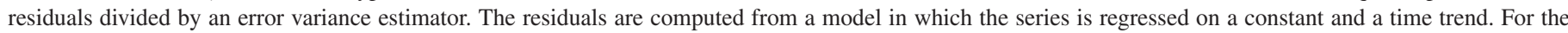
correction of the error term a Bartlett window with five lags was used to ensure the variance matrix was well behaved.

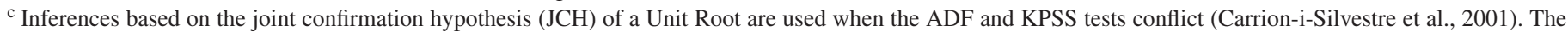

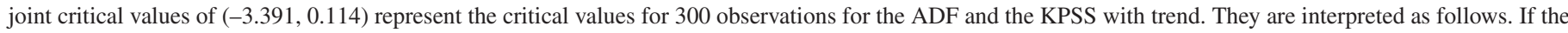

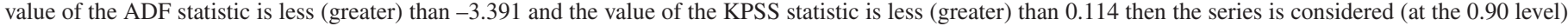
stationary (nonstationary). Otherwise, the series cannot be confirmed to be a unit root and is therefore considered stationary.

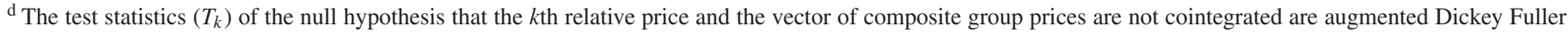

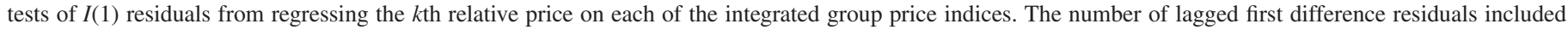

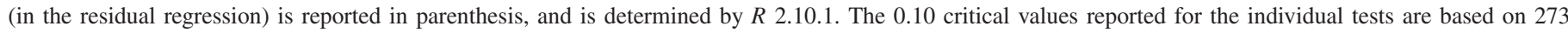
observations and eleven integrated explanatory variables, so that $k=12$ in MacKinnon (1996).

\section{Empirical results}

This section presents tests for valid aggregation of 19 elementary ground beef products and estimates of composite ground beef demand elasticities.

Tables 3, 4, and 5 summarize the GCCT tests for the proposed aggregation schemes. Following Lewbel (1996), two stationary tests were conducted: the Augmented Dickey-Fuller (ADF) test with a null of nonstationarity and the Kwaitkowski, Phillips, Schmidt, and Shin (KPSS) test with a null of stationarity. Having two tests introduces the possibility of conflicting results. Therefore, inferences based on the joint confirmation hypothesis $(\mathrm{JCH})$ of a unit root were used when the ADF and KPSS tests conflicted (Carrion-i-Silvestre et al., 2001). In all three test groups, the group price indices were nonstationary and 14 (Aggregation Scheme 1), 13 (Aggregation Scheme 2), and 14 (Aggregation Scheme 3) of the 19 relative prices were nonstationary; consequently, where relative prices were nonstationary aggregation rested on cointegration tests alone and where relative prices were stationary aggregation was deemed valid. Engle Granger tests were used to test for cointegration. Since the Engle Granger tests failed to reject the null of a spurious regression for all of the individual price comparisons, there was no need to perform family-wise tests (see Davis et al., 2000). The individual test results support the notion that each of the three ground beef aggregation schemes proposed in this study can be described by a valid composite consumer demand system. That is, we justify estimating a demand system 
Table 4

Generalized composite commodity theorem test results for aggregation scheme 2 (Brand Type Composites)

\begin{tabular}{|c|c|c|c|c|c|}
\hline Group and relative prices & Aggregate share $(\%)$ & ADF Test $H_{0}: I(1)^{\mathrm{a}}$ & KPSS Test $\mathrm{H}_{0}: I(0)^{\mathrm{b}}$ & $I(0)$ or $I(1) ?^{\mathrm{c}}$ & $\begin{array}{l}\text { Engle-Granger Test } \mathrm{H}_{0} \text { : } \\
\text { Not Cointegrated }(N C)^{\mathrm{d}}\end{array}$ \\
\hline & & $\tau_{t}$ & $\eta_{t}$ & & $T_{k}$ \\
\hline$R($ Local/Regional $)$ & & $-2.367(9)$ & $0.617(5)^{*}$ & $I(1)$ & \\
\hline$\rho(70-77 \%)$ & 52.90 & $-2.650(7)$ & $0.423(5)^{*}$ & $I(1)$ & $-2.413(7)$ \\
\hline$\rho(78-84 \%)$ & 15.32 & $-2.993(6)$ & $0.278(5)^{*}$ & $I(1)$ & $-2.081(6)$ \\
\hline$\rho(85-89 \%)$ & 4.58 & $-3.691(4)^{*}$ & $0.595(5)^{*}$ & $I(0)(\mathrm{JCH})$ & $N C$ \\
\hline$\rho(90-95 \%)$ & 7.06 & $-1.178(7)$ & $0.558(5)^{*}$ & $I(1)$ & $-1.307(11)$ \\
\hline$\rho(96-100 \%)$ & 20.15 & $-2.807(9)$ & $0.563(5)^{*}$ & $I(1)$ & $-2.575(10)$ \\
\hline$R$ (National) & & $-2.264(9)$ & $0.387(5)^{*}$ & $I(1)$ & \\
\hline$\rho(70-77 \%)$ & 8.35 & $-3.577(4)^{*}$ & $0.261(5)^{*}$ & $I(1)$ & $N C$ \\
\hline$\rho(78-84 \%)$ & 11.44 & $-1.427(10)$ & $0.736(5)^{*}$ & $I(0)(\mathrm{JCH})$ & $-2.068(10)$ \\
\hline$\rho(85-89 \%)$ & 17.27 & $-3.158(5)^{*}$ & $0.210(5)^{*}$ & $I(1)$ & $-3.021(8)$ \\
\hline$\rho(90-95 \%)$ & 36.85 & $-1.586(11)$ & $0.419(5)^{*}$ & $I(1)(\mathrm{JCH})$ & $-1.706(11)$ \\
\hline$\rho(96-100 \%)$ & 26.09 & $-1.685(10)$ & $0.529(5)^{*}$ & $I(1)$ & $-1.813(8)$ \\
\hline$R$ (Store) & & $-1.662(11)$ & $0.652(5)^{*}$ & $I(1)$ & \\
\hline$\rho(70-77 \%)$ & 20.88 & $-2.537(5)$ & $0.227(5)^{*}$ & $I(1)$ & $-1.927(4)$ \\
\hline$\rho(78-84 \%)$ & 12.63 & $-3.441(10)^{*}$ & $0.107(5)$ & $I(0)$ & $N C$ \\
\hline$\rho(85-89 \%)$ & 38.25 & $-3.834(4)^{*}$ & $0.189(5)^{*}$ & $I(0)(\mathrm{JCH})$ & $N C$ \\
\hline$\rho(90-95 \%)$ & 28.23 & $-1.882(11)$ & $0.663(5)^{*}$ & $I(1)$ & $-2.915(8)$ \\
\hline$R$ (Unbranded) & & $-2.347(7)$ & $0.464(5)^{*}$ & $I(1)$ & \\
\hline$\rho(70-77 \%)$ & 41.43 & $-2.015(8)$ & $0.335(5)^{*}$ & $I(1)$ & $-2.150(11)$ \\
\hline$\rho(78-84 \%)$ & 22.35 & $-3.097(11)$ & $0.615(5)^{*}$ & $I(1)$ & $-3.465(7)$ \\
\hline$\rho(85-89 \%)$ & 12.24 & $-4.328(7)^{*}$ & $0.165(5)^{*}$ & $I(0)(\mathrm{JCH})$ & $N C$ \\
\hline$\rho(90-95 \%)$ & 22.07 & $-3.908(11)^{*}$ & $0.064(5)$ & $I(0)$ & $N C$ \\
\hline$\rho(96-100 \%)$ & 1.91 & $-1.830(8)$ & $0.662(5)^{*}$ & $I(1)$ & $-2.618(11)$ \\
\hline $10 \%$ Critical Value & & -3.130 & 0.119 & $(-3.391,0.114)$ & -5.727 \\
\hline
\end{tabular}

Asterisk $(*)$ denotes rejection of the null at the 0.10 significance level.

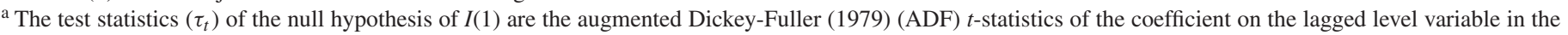

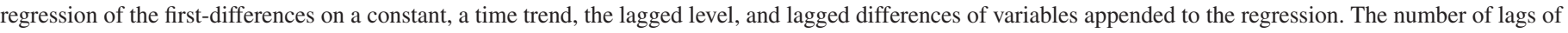
first differences is reported in parentheses and determined by $R$ 2.10.1.

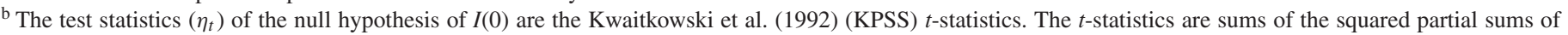

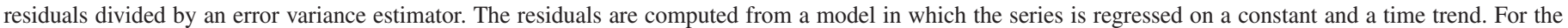
correction of the error term a Bartlett window with five lags was used to ensure the variance matrix was well behaved.

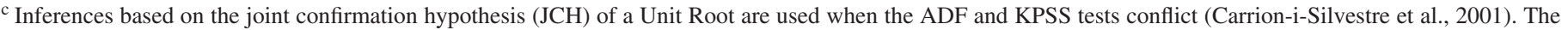

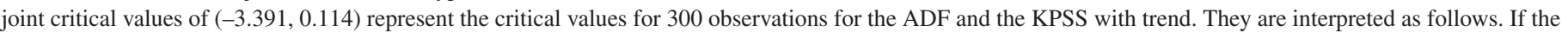

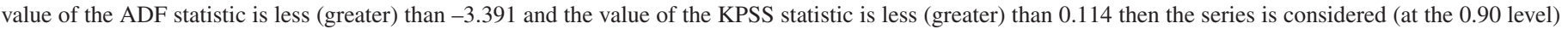
stationary (nonstationary). Otherwise, the series cannot be confirmed to be a unit root and is therefore considered stationary.

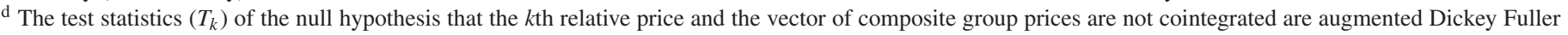

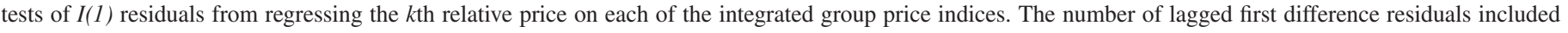

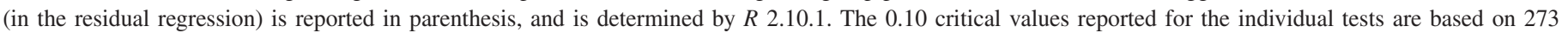
observations and eleven integrated explanatory variables, so that $k=12$ in MacKinnon (1996).

having five different lean percentages with brand types aggregated, a demand system having four different brand types with lean percentages aggregated, or estimating ground beef as a single composite aggregated across brand type and lean percentage. Previous research has suggested that the stochastic nature of the GCCT may support numerous aggregation schemes (Reed et al., 2005).

Table 6 presents estimates of the compensated own-, crossprice, and expenditure elasticities of the percent-lean-based ground beef demand system. The own-price elasticities are all negative and statistically significant at the $1 \%$ level. We are unaware of any other study that has estimated price elasticities for differentiated ground beef. Previous estimates are available for aggregate ground beef elasticities. For example, compensated own-price elasticity estimates for ground beef include Brester and Wohlgenant (1991) with an estimate of -1.02; Nayga and Capps (1994) with an estimate of -1.22; and Coffey et al. (2011) with an estimate of -1.08 . Our elasticity estimates range from -0.44 to -1.29 , being inelastic for $70-77 \%, 78-84 \%$, and $85-$ $89 \%$ lean and elastic for $90-95 \%$ and $96-100 \%$ lean.

The more inelastic demand for the lower lean percentage ground beef relative to leaner products suggests that consumer purchases of the cheaper, less lean, ground beef products are less responsive to own-price changes. Based on hedonic modeling, White (2010) found that $90 \%$ and higher lean ground beef had a retail price premium of a $\$ 1.00 / \mathrm{lb}$ or more relative to less than $85 \%$ lean products. We hypothesize that less lean ground beef is purchased by relatively lower-income consumers compared to the more expensive high lean product. Thus, less lean ground beef products may be more of a necessity for consumers that 
Table 5

Generalized composite commodity theorem test results for aggregation scheme 3 (Single Ground Beef Composite)

\begin{tabular}{|c|c|c|c|c|c|}
\hline Group and relative prices & Aggregate share $(\%)$ & ADF Test $\mathrm{H}_{0}: I(1)^{\mathrm{a}}$ & KPSS Test $\mathrm{H}_{0}: I(0)^{\mathrm{b}}$ & $I(0)$ or $I(1) ?^{\mathrm{c}}$ & $\begin{array}{l}\text { Engle-Granger Test } \mathrm{H}_{0} \text { : Not } \\
\text { Cointegrated }(N C)^{\mathrm{d}}\end{array}$ \\
\hline & & $\tau_{t}$ & $\eta_{t}$ & & $T_{k}$ \\
\hline$R$ (All Products) & & $-2.332(7)$ & $0.475(5)^{*}$ & $I(1)$ & \\
\hline$\rho($ Local/Regional 70-77\%) & 0.48 & $-3.116(4)$ & $0.541(5)^{*}$ & $I(1)$ & $-3.201(4)$ \\
\hline$\rho($ Local/Regional 78-84\%) & 0.14 & $-2.202(6)$ & $0.217(5)^{*}$ & $I(1)$ & $-2.143(6)$ \\
\hline$\rho($ Local/Regional 85-89\%) & 0.04 & $-4.767(3)^{*}$ & $0.420(5)^{*}$ & $I(0)(\mathrm{JCH})$ & $N C$ \\
\hline$\rho($ Local/Regional 90-95\%) & 0.06 & $-1.526(4)$ & $0.454(5)^{*}$ & $I(1)$ & $-1.486(4)$ \\
\hline$\rho($ Local/Regional 96-100\%) & 0.18 & $-5.652(5)^{*}$ & $0.224(5)^{*}$ & $I(0)(\mathrm{JCH})$ & $N C$ \\
\hline$\rho$ (National $70-77 \%)$ & 0.28 & $-3.161(9)^{*}$ & $0.269(5)^{*}$ & $I(1)(\mathrm{JCH})$ & $-3.647(8)$ \\
\hline$\rho$ (National $78-84 \%)$ & 0.39 & $-1.693(6)$ & $0.621(5)^{*}$ & $I(1)$ & $-1.781(6)$ \\
\hline$\rho$ (National $85-89 \%)$ & 0.59 & $-3.292(8)^{*}$ & $0.127(5)^{*}$ & $I(1)(\mathrm{JCH})$ & $-3.141(8)$ \\
\hline$\rho$ (National 90-95\%) & 1.25 & $-2.989(11)$ & $0.493(5)^{*}$ & $I(1)$ & $-2.455(11)$ \\
\hline$\rho$ (National 96-100\%) & 0.89 & $-2.592(8)$ & $0.550(5)^{*}$ & $I(1)$ & $-2.182(8)$ \\
\hline$\rho($ Store $70-77 \%)$ & 0.71 & $-3.416(4)^{*}$ & $0.300(5)^{*}$ & $I(0)(\mathrm{JCH})$ & $N C$ \\
\hline$\rho($ Store $78-84 \%)$ & 0.43 & $-3.099(11)$ & $0.728(5)^{*}$ & $I(1)$ & $-3.414(10)$ \\
\hline$\rho($ Store $85-89 \%)$ & 1.30 & $-1.481(11)$ & $0.536(5)^{*}$ & $I(1)$ & $-2.058(11)$ \\
\hline$\rho($ Store $90-95 \%)$ & 0.96 & $-3.073(7)$ & $0.382(5)^{*}$ & $I(1)$ & $-2.954(8)$ \\
\hline$\rho$ (Unbranded 70-77\%) & 38.25 & $-2.085(8)$ & $0.322(5)^{*}$ & $I(1)$ & $-2.120(8)$ \\
\hline$\rho$ (Unbranded 78-84\%) & 20.62 & $-3.076(11)$ & $0.609(5)^{*}$ & $I(1)$ & $-3.456(7)$ \\
\hline$\rho$ (Unbranded $85-89 \%)$ & 11.30 & $-4.202(7)^{*}$ & $0.174(5)^{*}$ & $I(0)(\mathrm{JCH})$ & $N C$ \\
\hline$\rho($ Unbranded $90-95 \%)$ & 20.36 & $-3.917(11)^{*}$ & $0.0623(5)$ & $I(0)$ & $N C$ \\
\hline$\rho$ (Unbranded $96-100 \%)$ & 1.76 & $-1.747(8)$ & $0.667(5)^{*}$ & $I(1)$ & $-2.605(11)$ \\
\hline 10 percent critical values & & -3.130 & 0.119 & $(-3.391,0.114)$ & -5.727 \\
\hline
\end{tabular}

Asterisk $(*)$ denotes rejection of the null at the 0.10 significance level.

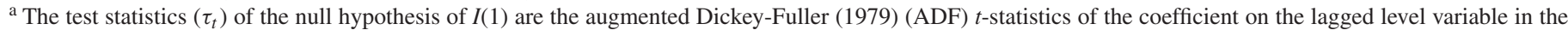

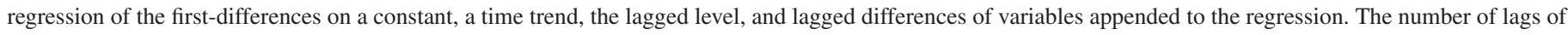
first differences is reported in parentheses and determined by $R$ 2.10.1.

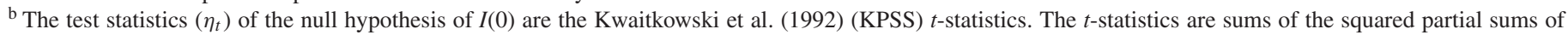

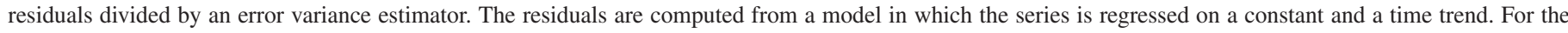
correction of the error term a Bartlett window with five lags was used to ensure the variance matrix was well behaved.

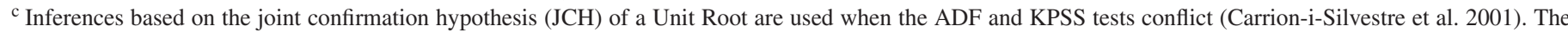

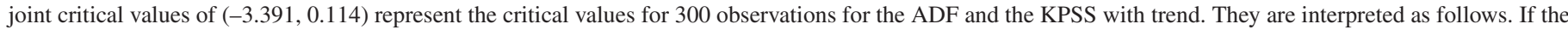

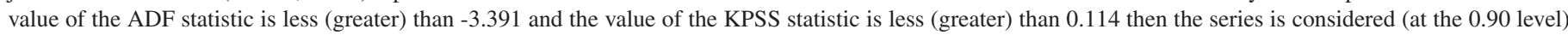
stationary (nonstationary). Otherwise, the series cannot be confirmed to be a unit root and is therefore considered stationary.

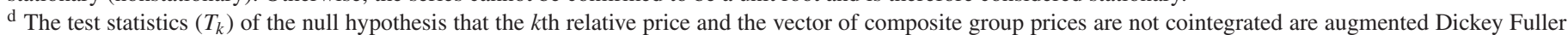

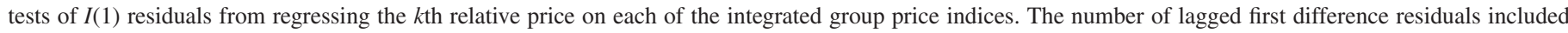

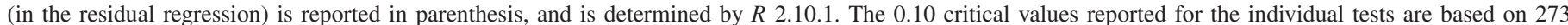
observations and eleven integrated explanatory variables, so that $k=12$ in MacKinnon (1996).

regularly purchase the product, compared to those who buy the leaner product.

All of the statistically significant cross-price elasticities are positive, as is expected for substitute products. The two lean percentages with the largest market shares are 70-77\% (40\% of revenue and $48 \%$ of quantity) and $90-95 \%$ (23\% of rev- enue and $17 \%$ of quantity). These two products tend to be the strongest substitutes for the others. Expenditure elasticities range from 1.22 for $70-77 \%$ to 0.48 for $96-100 \%$ lean. The 96-100\% lean product is a niche market having only $3 \%$ revenue and $2 \%$ quantity market share among the five products. The fact that the lowest lean product has the largest expenditure

Table 6

Lean percentage compensated price and expenditure elasticities

\begin{tabular}{|c|c|c|c|c|c|c|}
\hline \multirow[t]{2}{*}{ Elasticity of the quantity of } & \multicolumn{5}{|c|}{ With respect to the price of } & \multirow{2}{*}{$\begin{array}{l}\text { With respect to } \\
\text { expenditure }\end{array}$} \\
\hline & $70-77 \%$ & $78-84 \%$ & $85-89 \%$ & $90-95 \%$ & $96-100 \%$ & \\
\hline $70-77 \%$ & $-0.439^{* * *}$ & 0.044 & $0.105^{* * *}$ & $0.287^{* * *}$ & 0.004 & $1.223^{* * *}$ \\
\hline $78-84 \%$ & 0.082 & $-0.509^{* * *}$ & -0.010 & $0.424^{* * *}$ & $0.013^{*}$ & $0.759^{* * *}$ \\
\hline $85-89 \%$ & $0.304^{* * *}$ & -0.016 & $-0.869^{* * *}$ & $0.548^{* * *}$ & $0.033^{* * *}$ & $0.791^{* * *}$ \\
\hline $90-95 \%$ & $0.505^{* * *}$ & $0.395^{* * *}$ & $0.332^{* * *}$ & $-1.290^{* * *}$ & $0.059^{* * *}$ & $1.001^{* * *}$ \\
\hline $96-100 \%$ & 0.077 & $0.153^{*}$ & $0.245^{* * *}$ & $0.726^{* * *}$ & $-1.201^{* * *}$ & $0.484^{* * *}$ \\
\hline
\end{tabular}

Asterisks (*,**,***) indicate statistical significance at the 10,5 , and $1 \%$ levels. 
Table 7

Brand type compensated price and expenditure elasticities

\begin{tabular}{|c|c|c|c|c|c|}
\hline \multirow[t]{2}{*}{ Elasticity of the quantity of } & \multicolumn{4}{|c|}{ With respect to the price of } & \multirow{2}{*}{$\begin{array}{l}\text { With respect to } \\
\text { expenditure }\end{array}$} \\
\hline & Local/Regional & National & Store & Unbranded & \\
\hline Local/Regional & $-4.550^{* * *}$ & 0.077 & $0.931^{*}$ & $3.542^{* * *}$ & 0.291 \\
\hline National & 0.028 & $-2.199^{* * *}$ & $0.306^{* * *}$ & $1.865^{* * *}$ & $0.743^{* * *}$ \\
\hline Store & $0.400^{*}$ & $0.363^{* * *}$ & $-2.420^{* * *}$ & $1.656^{* * *}$ & $0.752^{* * *}$ \\
\hline Unbranded & $0.038^{* * *}$ & $0.055^{* * *}$ & $0.041^{* * *}$ & $-0.133^{* * *}$ & $1.021^{* * *}$ \\
\hline
\end{tabular}

Asterisks $(*, * *, * * *)$ indicate statistical significance at the 10,5 , and $1 \%$ levels.

elasticity again suggests that lower-income, budget-constrained consumers, may represent a large share of the consumers purchasing the product.

Table 7 presents elasticity estimates of the brand-type-based ground beef demand system. The own-price elasticities for brands are negative as expected. The elasticity estimates range from -0.13 to -4.55 , being inelastic for unbranded products and elastic for local/regional, national, and store brand types. An implied ranking of consumer's price sensitivity to own-price is (from most to least sensitive): (1) local/regional, (2) store, (3) national, and (4) unbranded. Consumers are more sensitive to price increases for less commonly known brands and less sensitive to price increases for well-known national brands and unbranded products. There are no published demand elasticities for branded ground beef to compare to our estimates. Richards and Padilla (2009) estimated elasticities that included fast food restaurants that specialize in hamburgers including McDonalds, Burger King, and Wendy's. They found elasticities for brand choice ranged from -2.9 to -3.8 for these three firms and for purchase quantity once in the establishment ranged from -1.6 to -1.9 .

As expected, all the brand type expenditure elasticities are positive and consistent with economic intuition. The local/regional brand type expenditure elasticity was not statistically significant at the 1-, 5-, or $10 \%$ level. All the crossprice elasticities are positive indicating the brand types are all substitutes as is expected with such closely related products. Unbranded ground beef (93\% of revenue and $94 \%$ of quantity) is relatively cheap compared to the branded products. As such, generic ground beef may represent a staple or necessity for budget-constrained households. In contrast, branded ground beef products have strong substitutes of other brands or the cheaper generic product.

\section{Conclusions and implications}

Beef producers and producer groups (and retailers) have invested significant resources in an attempt to better understand the beef purchasing decisions of consumers. Since ground beef is a growing share of total beef demand, branding, and labeling of ground beef has revealed important information about consumer preferences for beef and in particular about ground beef. By testing for valid aggregates and providing estimates of composite demand elasticities it is hoped that this article provides economists and policymakers with information regarding the effects of food and agricultural policies on consumers and producers that buy and produce ground beef.

Tests of commodity aggregation in this article apply the GCCT (Lewbel, 1996) to retail store based scanner data. Unlike tests based on separable utility functions, the tests presented in this article reveal whether the price and demand data that we use to estimate demand systems provide researchers and policy makers with reliable information on the demand for the goods that consumers actually buy. The empirical results presented in this article indicate that we obtain reliable information on consumers' actual ground beef purchases by grouping data according to either lean percentage or brand type. The results also suggest that we obtain reliable information by using the data to form a single ground beef composite.

\section{Acknowledgments}

The authors acknowledge John Lundeen of the National Cattlemen's Beef Association, The Beef Check-off program, and Dave Shepard of Meat Solutions LLC for providing the data. We appreciate the helpful comments provided by Gerald Shively and three anonymous reviewers.

\section{References}

Asche, F., Bremnes, H., Wessells, C.R., 1999. Product aggregation, market integration, and relationships between prices: An application to World Salmon Markets. Am. J. Agric. Econ. 81(3), 568-581.

Asche, F., Guttormsen, A., Tveterås, S., 2001. Aggregation over Different Qualities: Are there Generic Commodities? Econ. Bull. 3(13), 1-6.

Brester, G.W., Pascale, L., Goodwin, B.K., Hunt, M.C., 1993. Quantifying the effects of new product development: The case of low-fat ground beef. J. Agric. Resour. Econ. 18(2), 239-250.

Brester, G.W., Wohlgenant, M.K., 1991. Estimating interrelated demands for meats using new measures for ground beef and table cut beef. Am. J. Agric. Econ. 73(4), 1182-1194.

Capps Jr., O., Church, J., Love, H.A., 2003. Specification issues and confidence intervals in unilateral price effects analysis. J. Econometrics. 113(1), 3-31.

Capps Jr., O., Love, H.A., 2002. Econometric considerations in the use of electronic scanner data to conduct consumer demand analysis. Am. J. Agric. Econ. 84(3), 807-816. 
Capps, Jr., O., Seo, S.C., Nichols, J.P., 1997. On the estimation of advertising effects for branded products: An application to Spaghetti Sauces. J. Agric. Appl. Econ. 29(2), 291-302.

Carrion-i-Silvestre, J.L., Sanso-i-Rossello, A., Ortuno, M.A., 2001. Unit root and stationarity Tests' Wedding. Econ. Lett. 70(1), 1-8.

Coffey, B.K., Schroeder, T.C., Marsh, T.L., 2011. Disaggregated household meat demand with censored data. Appl. Econ. 43(18), 2343-2363.

Cotterill, R.W., 1994. Scanner data: New opportunities for demand and competitive strategy analysis. Agric. Resour. Econ. Rev. 23(2), 125-139.

Davis, G.C., 1998. Testing aggregation without separability in meat demand: An investigation of the generalized composite commodity theorem. Paper presented at American Agricultural Economics Association Annual Meeting. Salt Lake City Utah, 2-5 August.

Davis, G.C., Lin, N., Shumway, C.R., 2000. Aggregation without separability: Tests of the United States and Mexican agricultural production data. Am. J. Agric. Econ. 82(1), 214-230.

Deaton, A.S., Muellbauer, J., 1980. Economics and Consumer Behavior. Cambridge University Press, New York, NY.

Dickey, D.A., Fuller, W.A., 1979. Distribution of the estimators for autoregressive time series with a unit root. J. Am. Stat. Assoc. 74(366), 427-431.

Diewart, W.E., Wales, T.J., 1995. Flexible functional forms and tests for homogeneous separability. J. Econometrics. 67(2), 259-302.

Eales, J.S., Unnevehr, L.J., 1988. Demand for beef and chicken products: Separability and structural change. Am. J. Agric. Econ. 70(3), 521532

Eales, J., Hyde, J., Schrader, L.F., 1998. A note on dealing with poultry in demand analysis. J. Agric. Resour. Econ. 23(2), 558-567.

Granger, C.W.J., Hallman, J., 1988. The Algebra of I(1). Finance and Economics Discussion Series no. 45, Board of Governors of the United States Federal Reserve, Washington, DC.

Greene, W.H., 2003. Econometric analysis, $5^{\text {th }}$ edition. Prentice-Hall, Inc., Upper Saddle River, NJ.

Freshlook Marketing Group. Available at: http://freshlookmarketing.com/ (Accessed April 10, 2012).

Hicks, J.R., 1939. Value and Capital. Clarendon Press, Oxford.

Karagiannis, G., Mergos, G.J., 2002. Estimating theoretically consistent demand systems using cointegration techniques with application to Greek food data. Econ. Lett. 74(2), 137-143.

Kwaitkowski, D., Phillips, P.C.B., Schmidt, P., Shin, Y., 1992. Testing the null hypothesis of stationarity against the alternative of a unit root. J. Econometrics. 54(1-3), 159-178.

Lensing, C., Purcell, W.D., 2006. Impact of mandatory price reporting require- ments on level, variability, and elasticity parameter estimations for retail beef prices. Rev. Agric. Econ. 28(2), 229-239.

Leontief, W., 1936. Composite commodities and the problem of index numbers. Econometrica. 4(1), 39-59.

Lewbel, A., 1996. Aggregation without separability: A generalized composite commodity theorem. Am. Econ. Rev. 86(3), 524-543.

Lusk, J.L., Parker, N., 2009. Consumer preferences for amount and type of fat in ground beef. J. Agric. Appl. Econ. 41(1), 75-90.

MacKinnon, J.G., 1996. Numerical distribution functions for unit root and cointegration tests. J. Appl. Econometrics. 11(6), 601-618.

National Meat Case Study, 2010. A snap shot of Today's Retail Meat Case, 2010 National Meat Case Study Executive Summary. Sealed Air's Cryovac Food Packaging Unit, The Beef Checkoff Program, and the National Pork Board. Available at: http://www.beefretail.org/CMDocs/BeefRetail/ research/2010NationalMeatCaseStudy.pdf (Accessed April 10, 2012).

Nayga Jr., R.M., Capps Jr., O., 1994. Tests of weak separability in disaggregated meat products. Am. J. Agric. Econ. 76(4), 800-808.

Reed, A.J., Levedahl, J.W., Clark, J.S., 2003. Commercial disappearance and composite demand for food with an application to U.S. meats. J. Agric. Resour. Econ. 28(1), 53-70.

Reed, A.J., Levedahl, J.W., Hallahan, C., 2005. The generalized composite commodity theorem and food demand estimation. Am. J. Agric. Econ. 87(1), 28-37.

Richards, T.J., Padilla, L., 2009. Promotion and fast food demand. Am. J. Agric. Econ. 91(1), 168-183.

Seo, S.C., Capps, Jr., O., 1997. Regional variability of price and expenditure elasticities: The case of spaghetti sauces. Agribusiness: an Int. J. 13(6), $672-695$.

Shumway, C.R., Davis, G.C., 2001. Does consistent aggregation really matter? Australian J. Agric. Resour. Econ. 45(2), 161-194.

Theil, H., 1980. The system-wide approach to microeconomics. The University of Chicago Press, Chicago, IL.

Tonsor, G.T., 2012. Annual, All Fresh Beef Demand Index (1990=100). Department of Agricultural Economics, Kansas State University. Available at: http://www.agmanager.info/livestock/marketing/graphs/Tonsor/ Annual_AllFreshBeefDemandIndex_1990.htm (Accessed April 10, 2012).

White, K.L., 2010. What is the future of brand name beef: A price analysis of branding incentives and other attributes for retail beef using sales scanner data. Unpublished MS Thesis, Kansas State University.

Williams, S.P., Shumway, C.R., 2000. Trade liberalization and agricultural chemical use: United States and Mexico. Am. J. Agric. Econ. 82(1), 183199. 
lowa State University does not discriminate on the basis of race, color, age, religion, national origin, sexual orientation, gender identity, genetic information, sex, marital status, disability, or status as a U.S. veteran. Inquiries can be directed to the Director of Equal Opportunity and Compliance, 3280 Beardshear Hall, (515) 294-7612. 